\title{
MODELLING SINGLE TREE STRUCTURE WITH TERRESTRIAL LASER SCANNER
}

\author{
H. Yurtseven ${ }^{\mathrm{a},}$ *, M. Akgül ${ }^{\mathrm{b}}$, S. Gülci ${ }^{\mathrm{c}}$ \\ a* Istanbul University Faculty of Forestry, Department of Surveying and Cadastre, Istanbul, Turkey (hyurtseven@istanbul.edu.tr) \\ ${ }^{b}$ Istanbul University Faculty of Forestry, Department of Forest Construction and Transportation, Istanbul, Turkey \\ (makgul@istanbul.edu.tr) \\ ${ }^{c}$ Kahramanmaras Sutcu Imam University, Faculty of Forestry, 46100 Kahramanmaras, Turkey (sgulci@ksu.edu.tr)
}

KEY WORDS: Precision forestry, terrestrial laser scanner, 3D modelling

\begin{abstract}
:
Recent technological developments, which has reliable accuracy and quality for all engineering works, such as remote sensing tools have wide range use in forestry applications. Last decade, sustainable use and management opportunities of forest resources are favorite topics. Thus, precision of obtained data plays an important role in evaluation of current status of forests' value. The use of aerial and terrestrial laser technology has more reliable and effective models to advance the appropriate natural resource management. This study investigates the use of terrestrial laser scanner (TLS) technology in forestry, and also the methodological data processing stages for tree volume extraction is explained.
\end{abstract}

Z+F Imager 5010C TLS system was used for measure single tree information such as tree height, diameter of breast height, branch volume and canopy closure. In this context more detailed and accurate data can be obtained than conventional inventory sampling in forestry by using TLS systems. However the accuracy of obtained data is up to the experiences of TLS operator in the field. Number of scan stations and its positions are other important factors to reduce noise effect and accurate 3D modelling. The results indicated that the use of point cloud data to extract tree information for forestry applications are promising methodology for precision forestry.

\section{INTRODUCTION}

Forest structure information such as tree height, diameter of breast height, canopy closure are important data for modelling and assessing stand structure. And also forest structure information can be used for traditionally, forest inventories are done on the ground by field (Means et al, 2000). Nowadays, airborne based LIDAR and terrestrial laser scanner based data has become a more important in forest management (Bienert et al, 2006). Terrestrial laser scanning technology provides highly detailed 3D data can be used in measuring (Vonderach et al. 2012; Eysn et al. 2013; Saarinen et al. 2017; Akgül et al. 2016)

The objective of the study was point cloud based 3D modelling of single tree to calculate individual parameters with high accuracy.

\section{MATERIAL AND METHODS}

\subsection{Study Area}

The study area is located on Istanbul University Faculty of Forestry campus close to Sariyer in the city of Istanbul in Turkey (Figure 1).

\subsection{Point Cloud Data Acquisition}

In the context aim of the study, TLS measurements were completed with phase based scanner Z+F Imager 5010C on high mode (Table 1). According to the factory data of the terrestrial laser scanner system which is used in this research (ZF5010C), the angular resolution is 0.018 degrees (vertical and horizontal) at "Super High" mode, which provides a distance of 0.0164 meters between the two points in the point cloud data at a distance of 10 meters from the single scan station in the horizontal plane.
In the study, to generate 3D model of the tree, TLS data generated from 6 scan stations which were installed around the tree.

Throughout the study area, scan stations were established at 5 10 meter distance between two scan stations. TLS was installed approximately at $2 \mathrm{~m}$ height at each scan station. 6 portable target were used for point cloud registration (Figure 2).

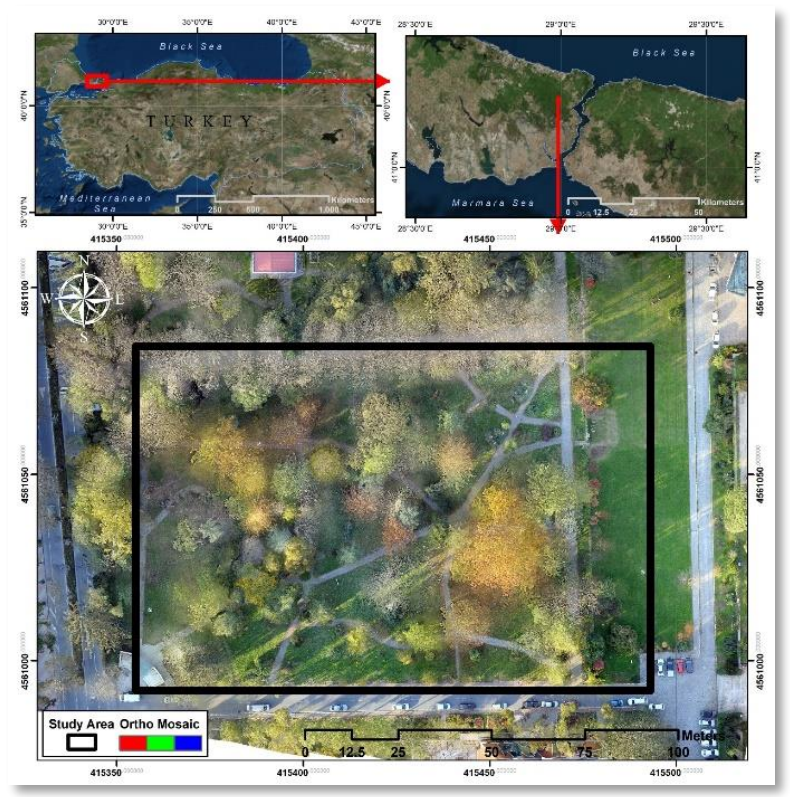

Figure 1. Location map of the study area

All raw scans were registered by using Z+F Laser Control V8.6.0 commercial software (Figure 3). Registrations were 
georeferenced with using portable targets. After the georeferencing, noise data were eliminated using range, intensity and thin filter algorithm.
Average point-to-point distance has obtained as 0.0008 meter ( 0.8 milimeter) in registered point cloud data.

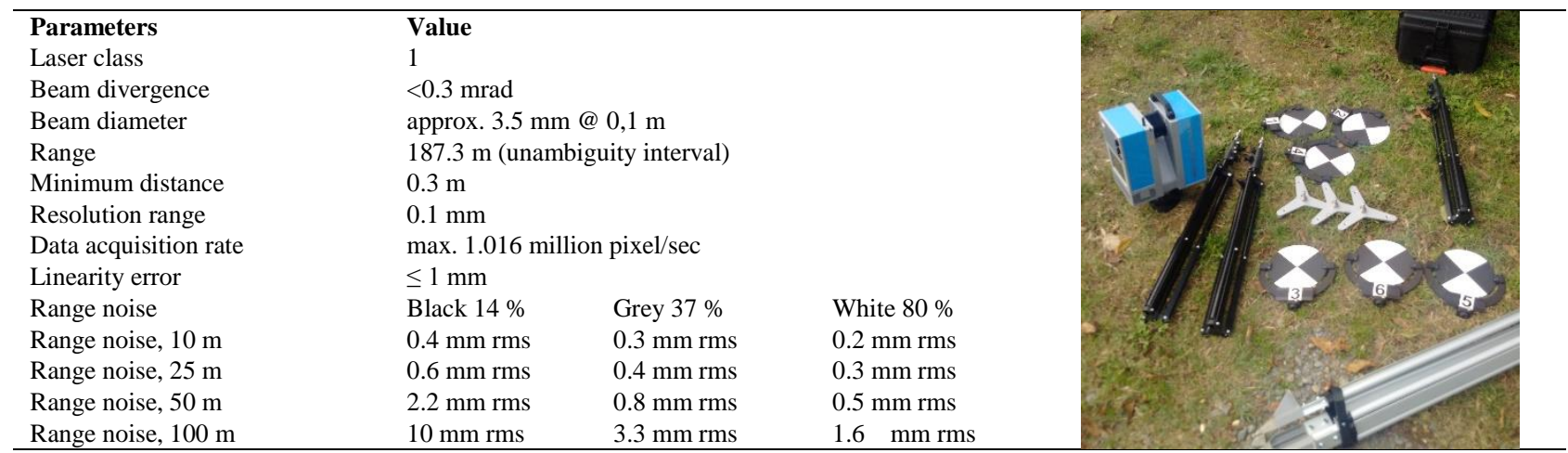

Table 1. Technical specification of laser scanner

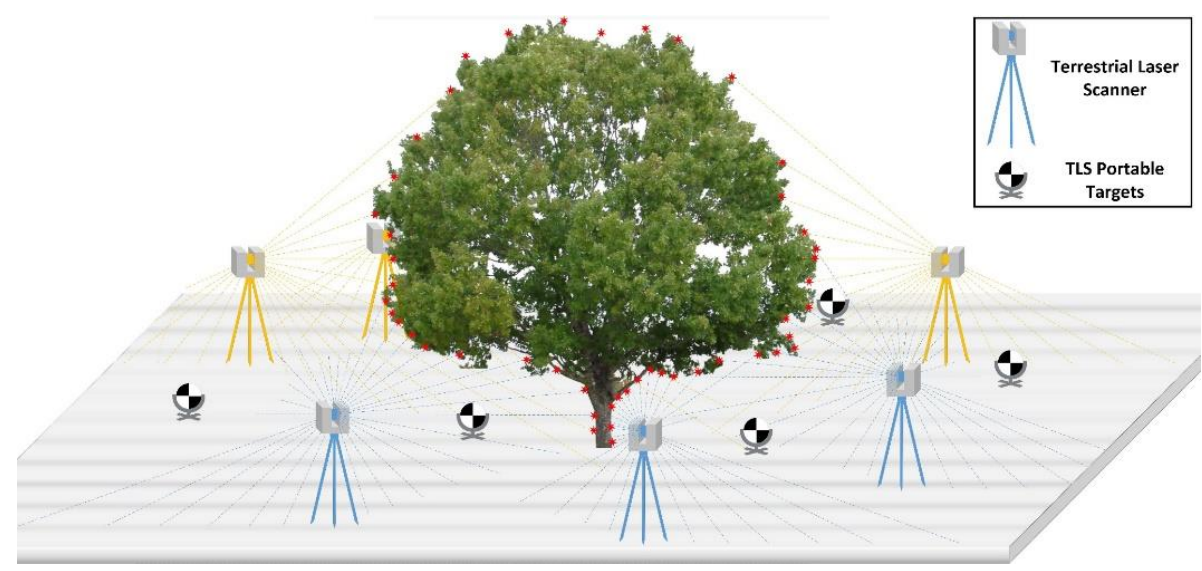

Figure 2. Location of scan stations

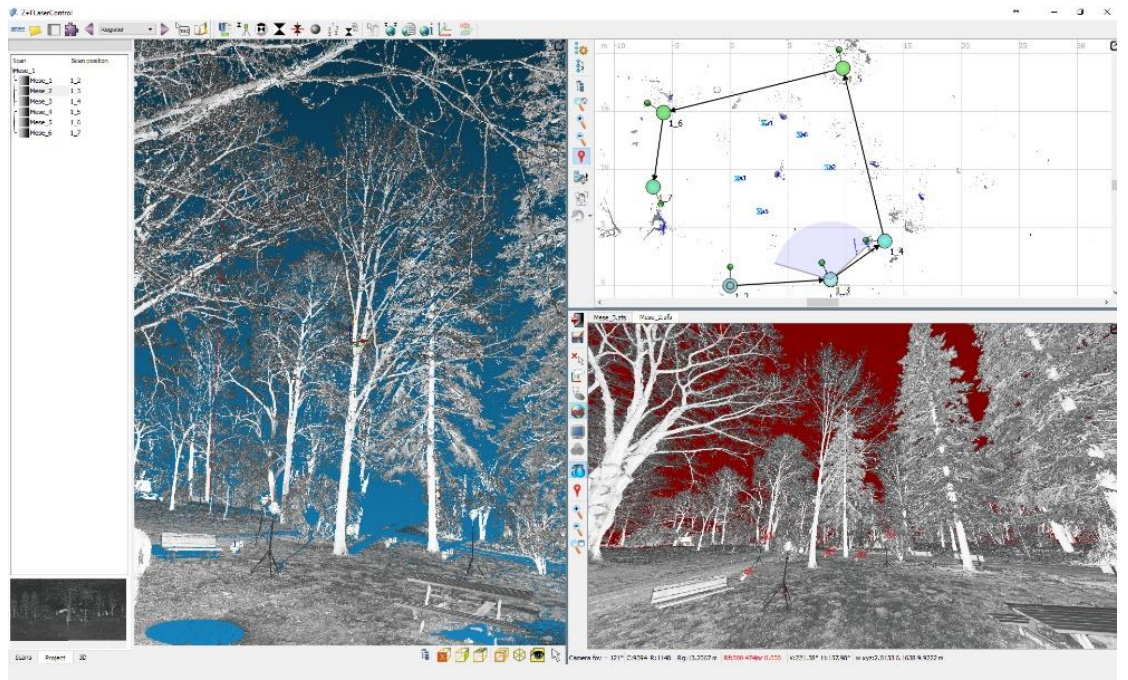

Figure 3. Registration screen of point cloud data

\subsection{Extraction of Individual Tree Parameters}

In this study, SimpleTree software which is available free, opensource software was used for data processing. This software provides for computing tree segmentation and capable of modelling high accurate cylindrical tree models from point cloud. (Hackenberg et al, 2015)
This entire processing and analysis works were conducted on workstation computer which has $2.6 \mathrm{GHz}$ processor and $64 \mathrm{~GB}$ Ram running with Windows 8 Enterprise and 64-bit operating system. 


\section{RESULTS AND DISCUSSION}

In the study, a single tree was scanned by using TLS to obtain high accuracy tree parameters. Then, registered and filtered point cloud data of tree was analyzed in SimpleTree software. According to analyses results, diameter of breast height of measured tree was calculated as $26.572 \mathrm{~cm}$ while tree height calculated as 13.978 meter (Table 2) (Figure 4). These calculated results are parameters that are the most considered in forestry studies which commonly measure with conventional measurement methods.

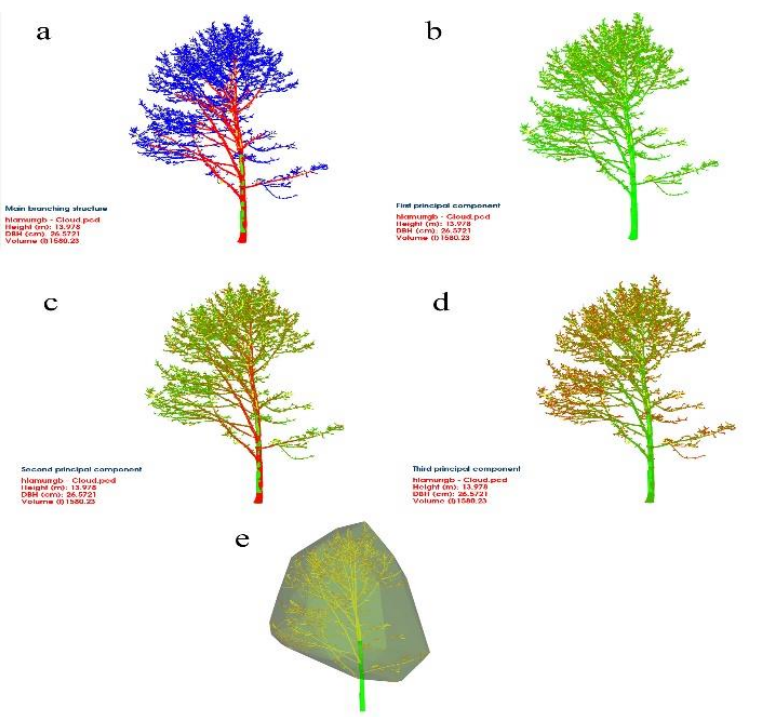

Figure 4. Extraction of branching order and tree components a) main branching order, b) first principle component, c) second principle component, d) third principle component e) 3D canopy modelling

\begin{tabular}{lc}
\hline \multicolumn{1}{c}{ Parameter } & Value \\
Volume $\left[\mathrm{m}^{3}\right]$ & 1.580 \\
Solid Volume $\left[\mathrm{m}^{3}\right]$ & 0.571 \\
Stem Volume $\left[\mathrm{m}^{3}\right]$ & 0.576 \\
Height $[\mathrm{m}]$ & 13.978 \\
Length $[\mathrm{m}]$ & 17.430 \\
DBH $[\mathrm{cm}]$ & 26.572 \\
VolUntilFirstBranch $\left[\mathrm{m}^{3}\right]$ & 0.310 \\
VolUntilCrown $\left[\mathrm{m}^{3}\right]$ & 0.310 \\
Crown base $[\mathrm{m}]$ & 0.863 \\
CrownVolume $\left[\mathrm{m}^{3}\right]$ & 52.855 \\
CrownArea $\left[\mathrm{m}^{2}\right]$ & 34.586 \\
CrownProjectionArea $\left[\mathrm{m}^{2}\right]$ & 70.838 \\
\hline \multicolumn{2}{c}{ Table $2 . \mathrm{Detailed} \mathrm{parameter} \mathrm{of} \mathrm{tree}^{2}$}
\end{tabular}

Table 2. Detailed parameter of tree

Contrary to conventional forest inventory methods, the point cloud based data provide extra detailed parameters such as branch ordering and it's volume (Table 3), 3D canopy modelling, canopy parameters etc. And also TLS based 3D modelling result can be used in stem modelling (Figure 5) which will be used in timber volume estimation in forestry.

\begin{tabular}{cc}
\hline Branch order & Volume \\
1 & 0.575814 \\
2 & 0.424947 \\
3 & 1.128415 \\
4 & 1.038678 \\
5 & 0.382939 \\
6 & 0.175417 \\
7 & 0.000702 \\
\hline
\end{tabular}

Table 3. Branch volumes of tree
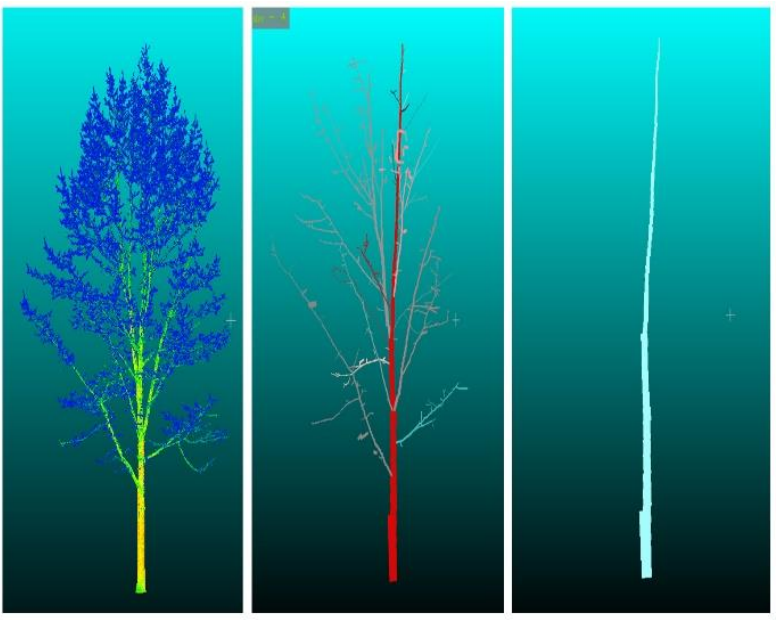

Figure 5. Extraction of main stem

The results indicated that, terrestrial laser scanner is an effective measurement tool to provide high accuracy and objective results for 3D modelling of tree structure parameters. One of the most important stage in modelling is noise cleaning. And also scan station number is important for right modelling. In the determining of scan station placement, users have to consider environmental obstacle which may be restrict scanning.

\section{REFERENCES}

Akgül, M., Yurtseven, H., Akburak, S., \& Çoban, S. (2016). Determination of some tree parameters using terrestrial laser scanner in urban green areas. Journal of the Faculty of Forestry Istanbul University İstanbul Üniversitesi Orman Fakültesi Dergisi, 66(2), 445-458.

Bienert, A., Scheller, S., Keane, E., Mullooly, G., \& Mohan, F. (2006). Application of terrestrial laser scanners for the determination of forest inventory parameters. International Archives of Photogrammetry, Remote Sensing and Spatial Information Sciences, 36(5)

Eysn L., Pfeifer N., Ressl C., Hollaus M., Grafl A., Morsdorf F. (2013). Practical approach for extracting tree modelsin forest environments based on equirectangular projections of terrestrial laser scans. Remote Sensing 5: 5424-5448.

Hackenberg, J., Spiecker, H., Calders, K., Disney, M., \& Raumonen, P. (2015). SimpleTree - an efficient open source tool to build tree models from TLS clouds. Forests, 6(11), 4245-4294.

Means, J. E., Acker, S. A., Fitt, B. J., Renslow, M., Emerson, L., \& Hendrix, C. J. (2000). Predicting forest stand characteristics with airborne scanning lidar. Photogrammetric Engineering and Remote Sensing, 66(11), 1367-1372.

Saarinen, N., Kankare, V., Vastaranta, M., Luoma, V., Pyörälä, J., Tanhuanpää, T., ... \& Yu, X. (2017). Feasibility of Terrestrial laser scanning for collecting stem volume information from single trees. ISPRS Journal of Photogrammetry and Remote Sensing, 123, 140-158

Vonderach C., Voegtle T., Adler P. (2012). Voxel-based approach for estimating urban tree volume from terrestrial laser scanning data. International Archives of Photogrammetry, Remote Sensing and Spatial Information Sciences 39: 451-456 